\title{
Long Distance Radical Cation Hopping in DNA: The Effect of Thymine-Hg(II)-Thymine Base Pairs
}

\author{
Joshy Joseph and Gary B. Schuster* \\ School of Chemistry and Biochemistry, Georgia Institute of Technology, \\ Atlanta, GA 30332 \\ schuster@gatech.edu
}

Supporting Information (OL070135A)

(General experimental procedures, Mass spectra of oligonucleotide strands and CD spectra of the duplexes)

\section{Materials and Methods}

Unmodified DNA oligomers and anthraquinone (AQ) containing complementary oligomer (Figure 2) were synthesized as described elsewhere on an Applied Biosystems DNA synthesizer. ${ }^{1}$ The extinction coefficients of the oligomers were calculated using the Online Biopolymer Calculator ${ }^{2}$ and the absorbance was measured at $260 \mathrm{~nm}$. Reverse-phase HPLC of oligomers were performed on a Hitachi system using a Microsorb-MV C18 reversed-phase column (4.6 mm i.d. x $25 \mathrm{~cm}$ length, $300 \AA$ ) from Rainin with an oven temperature maintained at $65{ }^{\circ} \mathrm{C}$. The oligonucleotides gave the expected mass spectra as shown in Figures S1-S3. UV melting and cooling curves were recorded on a Cary $1 \mathrm{E}$ spectrophotometer equipped with a multicell block, temperature controller, and sample transport accessory. CD spectrum was recorded in JASCO J-720 Spectropolarimeter. Both DNA(1) and DNA(2) in the presence and absence of 
$\mathrm{Hg}^{2+}$ ions showed CD spectra characteristic of B-form DNA duplex as shown in Figure S4.

\section{Cleavage analysis by radiolabeling and polyacrylamide gel electrophoresis (PAGE)}

AQ containing DNA oligomer was radiolabeled at the 3 '-end with [ $\alpha$ ${ }^{32}$ P]ATP and TdT enzyme. The radiolabeled DNA was purified by $20 \%$ PAGE. In general, samples for irradiation were prepared by hybridizing a mixture of "cold" and radiolabeled $(10,000 \mathrm{cpm})$ oligonucleotides with the non-AQ complementary strands in sodium phosphate buffer $(\mathrm{pH}=7.0)$ and water (to a total volume of 20 $\mu \mathrm{L}$ ). Hybridization was achieved by heating the samples at $90{ }^{\circ} \mathrm{C}$ for $5 \mathrm{~min}$, followed by slow cooling to room temperature. Samples were irradiated in microcentrifuge tubes in a Rayonet photoreactor (Southern New England Ultraviolet Company, Barnsford, CT) equipped with 8 x $350 \mathrm{~nm}$ lamps at ca. 30 ${ }^{\circ} \mathrm{C}$. After irradiation, the samples were precipitated once with cold ethanol (100 $\mu \mathrm{L})$ in the presence of glycogen, washed with $80 \%$ ethanol $(100 \mu \mathrm{L})$, dried (speedvac, low heat) and treated with piperidine (100 mL, $1 \mathrm{M}$ solution) at $90{ }^{\circ} \mathrm{C}$ for 30 min. After evaporation of the piperidine (speedvac, medium heat), lypholization twice with water $(20 \mu \mathrm{L})$, and suspension in denaturing loading buffer, the samples (3000 cpm) were electrophoresed on a 20\% 19:1 acrylamide:bis-acrylamide gel containing urea $(7 \mathrm{M})$ at $70 \mathrm{~W}$ for $90 \mathrm{~min}$. The gels were dried, and the cleavage sites were visualized by autoradiography. Quantization of cleavage bands was performed on a phosphorimager.

\section{Preparation of duplex containing Thymine-Hg(II)-Thymine base pairs ${ }^{3}$}

DNA(2) contains two TT mismatches between the second and third GG steps. Calculated amounts of $\mathrm{Hg}^{2+}$ salt solution was added to hybridized samples of duplex DNA(2) and the mixture was kept at room temperature for at least $3 \mathrm{~h}$. 
The formation of duplex containing the thymine-Hg(II)-thymine mismatches was confirmed by DNA melting $\left(\mathrm{T}_{\mathrm{m}}\right)$ experiments. Control experiments were done with DNA(1) to make sure that $\mathrm{Hg}^{2+}$ is not affecting the DNA structure.

\section{References:}

1. Gasper, S. M.; Schuster, G. B. J. Am. Chem. Soc. 1997, 119, 12762-12771.

2. http://www.basic.northwestern.edu/biotools/oligocalc.html.

3. Miyake, Y.; Togashi, H.; Tashiro, M.; Yamaguchi, H.; Oda, S.; Kudo, M.; Tanaka, Y.; Kondo, Y.; Sawa, R.; Fujimoto, T.; Machinami, T.; Ono, A. J. Am. Chem. Soc. 2006, 128, 2172-2173. 


\section{5’AQ-AATTGGTTGGTTGGTTGGTTGGTTGGTTATAT-3’}

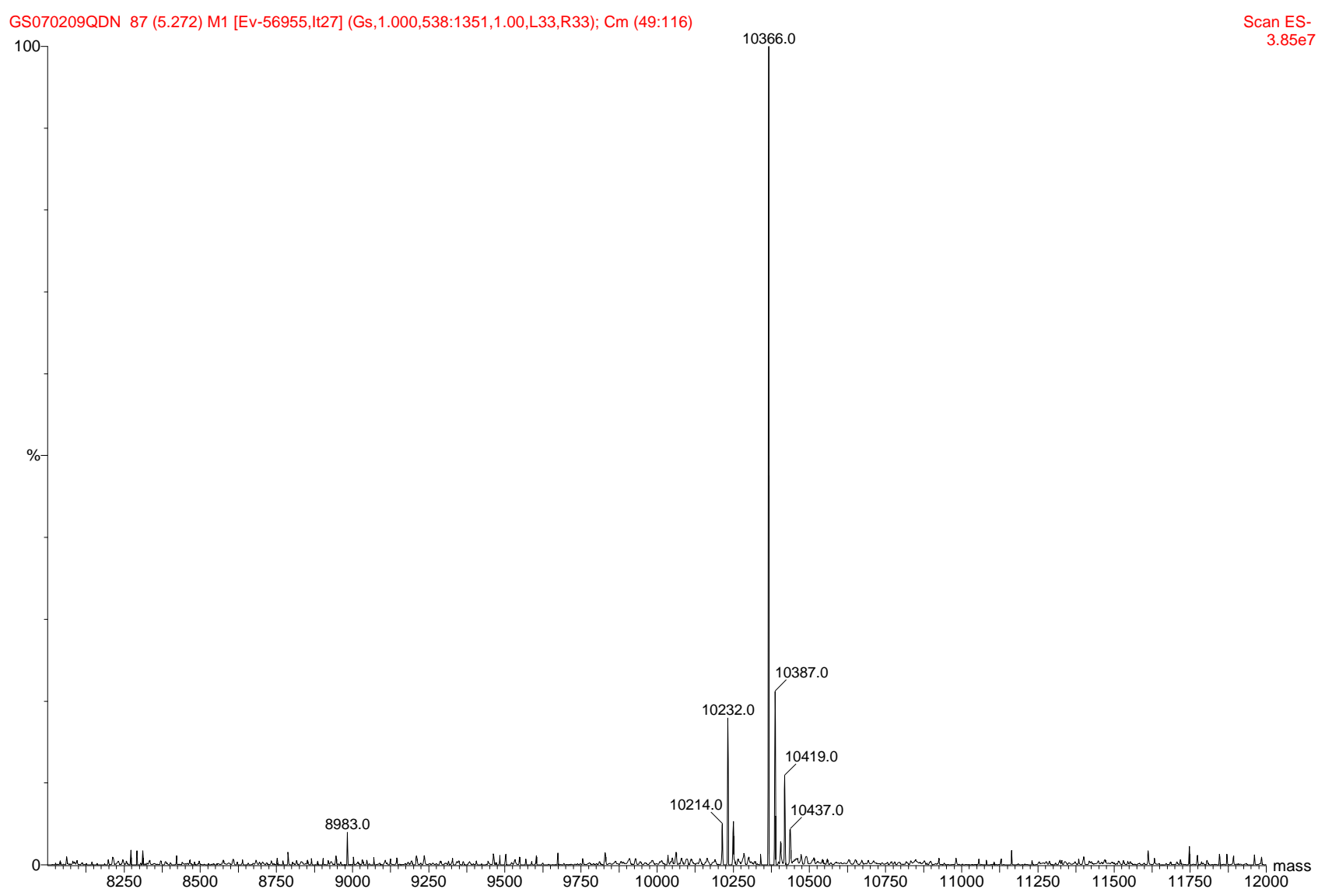

Figure S1. Mass spectrum of Anthraquinone (AQ) containing duplex used in this study. Calculated mass for the strand is 10365.6 and the small additional peaks correspond to the association of one or more sodium ions during the mass spectrometric experiment. 


\section{3’-TTAACCAACCAACCAACCAACСAACCAATATA-5'}

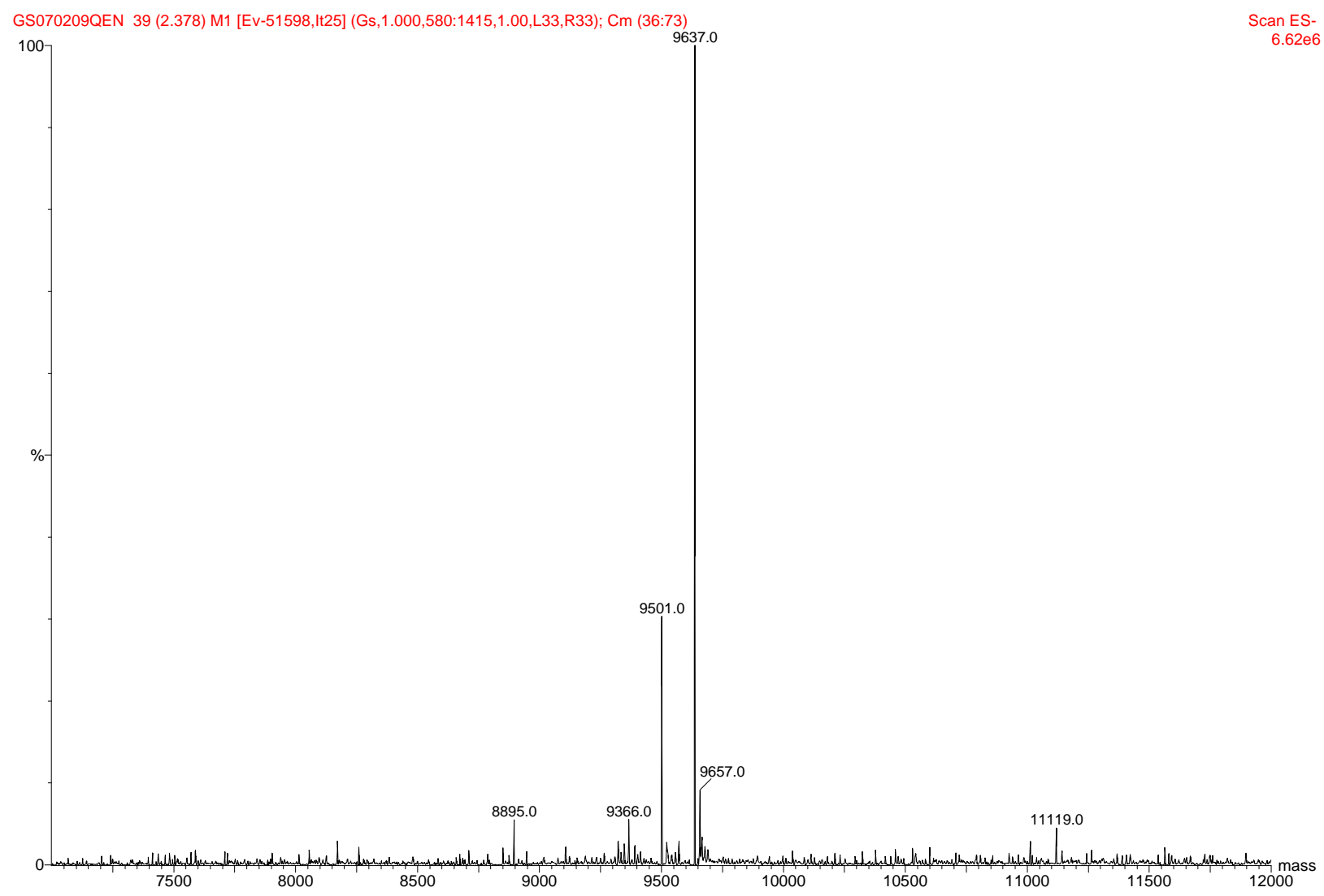

Figure S2. Mass spectrum of complementary strand for DNA(1). Calculated mass for the strand is 9636.4 and the small additional peaks correspond to the association of one or more sodium ions during the mass spectrometric experiment. 


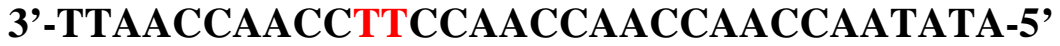

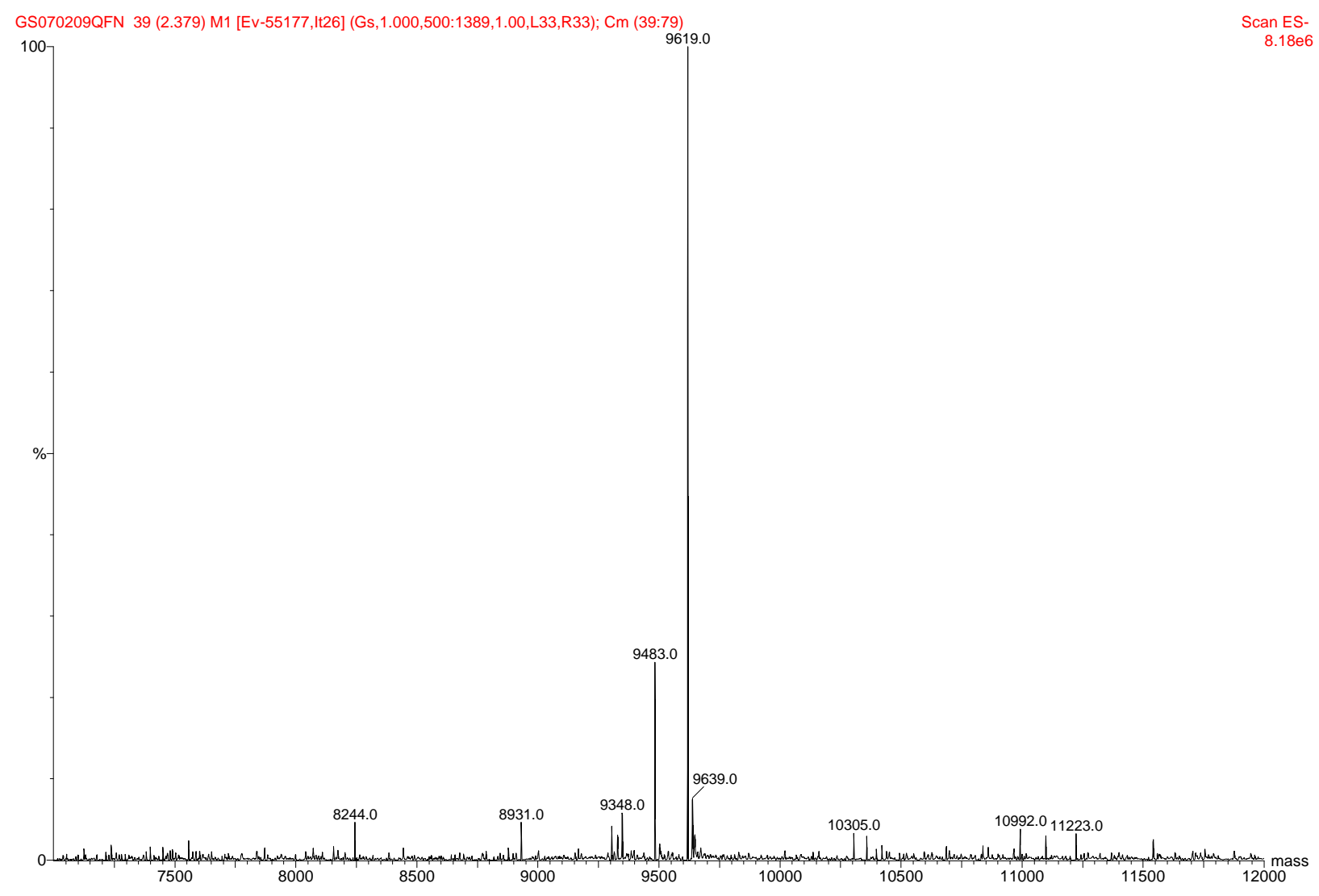

Figure S3. Mass spectrum of complementary strand for DNA(2). Calculated mass for the strand is 9618.3 and the small additional peaks correspond to the association of one or more sodium ions during the mass spectrometric experiment. 

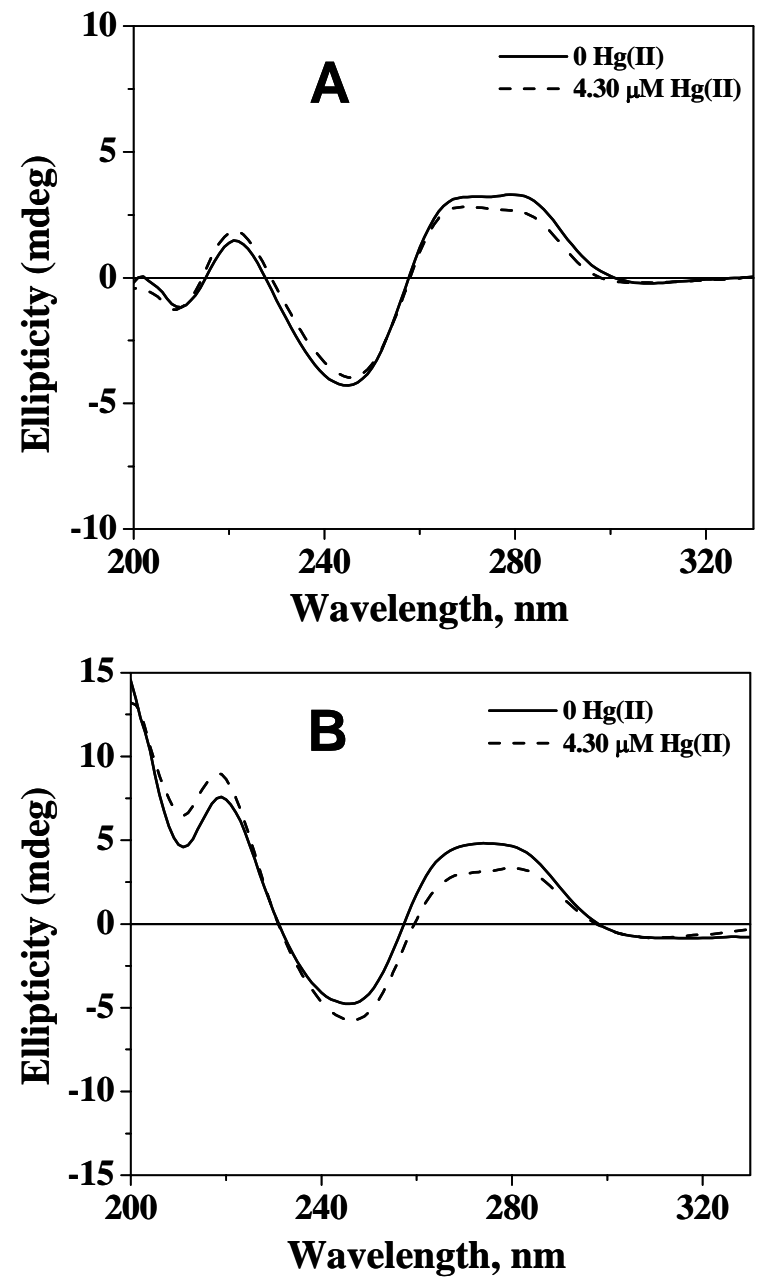

Figure S4. Circular dichroism (CD) spectra of (A) DNA(1) and (B) DNA(2) in presence and absence of $\mathrm{Hg}^{2+}$ salts. The duplex concentration is $1 \mu \mathrm{M}$ in both cases. 